\title{
Electrochemical study of asymmetric aqueous supercapacitors based on high density oxides: C/ $\mathrm{Ba}_{0.5} \mathrm{Sr}_{0.5} \mathrm{Co}_{0.8} \mathrm{Fe}_{0.2} \mathrm{O}_{3-\delta}$ and $\mathrm{FeWO}_{4} / \mathrm{Ba}_{0.5} \mathrm{Sr}_{0.5} \mathrm{CO}_{0.8} \mathrm{Fe}_{0.2} \mathrm{O}_{3-\delta}$
}

Pierre Lannelongue ${ }^{1,3}$, Steven Le $\operatorname{Vot}^{1,3}$, Olivier Fontaine ${ }^{1,3}$, Thierry Brousse $^{2,3}$ and Fréderic Favier ${ }^{1,3, *}$

${ }^{1}$ Institut Charles Gerhardt Montpellier (ICGM), UMR 5253, Université de Montpellier, CNRS, 34095 Montpellier Cedex 5, France

${ }^{2}$ Institut des Matériaux Jean Rouxel (IMN), UMR 6502, Université de Nantes, CNRS, 44322 Nantes Cedex 3, France

${ }^{3}$ Réseau sur le Stockage Electrochimique de l'énergie (RS2E), FR CNRS 3459, France *

\begin{abstract}
Two asymmetric aqueous electrochemical capacitors operated in $5 \mathrm{M} \mathrm{LiNO}_{3}$ are reported: $\mathrm{C} / \mathrm{Ba}_{0.5} \mathrm{Sr}_{0.5} \mathrm{Co}_{0.8} \mathrm{Fe}_{0.2} \mathrm{O}_{3-\delta}$ (BSCF) and $\mathrm{FeWO}_{4} / \mathrm{BSCF}$, with activated carbon and $\mathrm{FeWO}_{4}$ (synthesized by a precipitation method) as negative electrodes, respectively, and BSCF (synthesized by a modified glycine-nitrate process) as positive electrodes. These two devices were operated between 0 and $1.6 \mathrm{~V}$ and between 0 and $1.4 \mathrm{~V}$, respectively. They demonstrated a remarkable cycling ability with a high capacitance retention over 10,000 and 45,000 cycles, respectively. Thanks to the high density of BSCF, the C/BSCF device exhibits a volumetric energy density up to $2.7 \mathrm{Wh} . \mathrm{L}^{-1}$ at low current densities. This study demonstrates the advantages and limits of the use of high density multicationic oxides with pseudocapacitive behavior to improve the volumetric energy density of aqueous electrochemical capacitors.
\end{abstract}




\section{Keywords}

Aqueous electrochemical capacitors; Supercapacitors; Asymmetric devices; Volumetric energy density; BSCF; $\mathrm{FeWO}_{4}$; Perovskite.

\section{Introduction}

Electrochemical capacitors, also called supercapacitors, present intermediate performance between batteries and conventional capacitors [1] . Currently, commercialized electrochemical capacitors are electrochemical double layer capacitors (EDLCs) using activated carbon as electrodes. Their specific energy and power densities are about $10 \mathrm{Wh} \cdot \mathrm{kg}^{-1}[\underline{1}]$ and $10 \mathrm{~kW} \cdot \mathrm{kg}^{-1}$ [2] , respectively. However, their volumetric energy density is low, typically between 5 and 7 Wh. $\mathrm{L}^{-1}$. As such, EDLCs are not the ideal devices for power applications where the volume dedicated to energy storage is limited, such as in modern electrical terrestrial vehicles. Another type of electrochemical capacitors has been developed over the past two decades, using materials showing a pseudocapacitive behavior. The pseudocapacitive charge storage process induces a similar electrochemical signature to that of capacitive process, but its origin is faradic and involves fast and reversible redox reactions [1,3]. Such behavior has been observed for various electrode materials including metal oxides such as $\mathrm{RuO}_{2}$ [ㄴ-6], $\mathrm{MnO}_{2}[\underline{7-}$ 9], $\mathrm{Fe}_{3} \mathrm{O}_{4}[10,11]$, but also nitrides such as $\mathrm{VN}[12,13]$ and $\mathrm{Mo}_{\mathrm{x}} \mathrm{N}[\underline{14}]$, conducting polymers [15] or Mxenes [16]. Thanks to their high density compared to that of activated carbon, pseudocapacitive oxides are attractive materials to improve the volumetric energy density of electrochemical capacitors. As such, Goubard-Bretesché et al. predicted a volumetric energy density of a symmetrical electrochemical capacitor $\mathrm{MnO}_{2} / \mathrm{MnO}_{2}$ (bulk density: 4.5 g.cm ${ }^{-3}$ ) twice greater than that of a symmetrical carbon/carbon device (bulk density: $2.09-2.23 \mathrm{~g} . \mathrm{cm}^{-3}$ ) while keeping the same gravimetric specific energy [17]. 
Thus, high density pseudocapacitive oxides have to be considered to improve the volumetric energy density of electrochemical capacitors. This is in the last few years only that multicationic oxides have been studied as electrode materials for electrochemical capacitors [18]. Among them, $\mathrm{ABO}_{3}$ perovskite materials [19-23], $\mathrm{AB}_{2} \mathrm{O}_{4}$ spinel materials [24-27], $\mathrm{MWO}_{4}$ tungstate materials [28] or $\mathrm{A}_{2} \mathrm{~B}_{2} \mathrm{O}_{7}$ pyrochlore materials [29] have been considered. These materials present high densities but also specific capacitances close to that of standard activated carbon. In previous papers, some of us have reported the attractive properties of two oxides to be used as electrode materials for electrochemical capacitors: $\mathrm{FeWO}_{4}$ [료 $]$ and

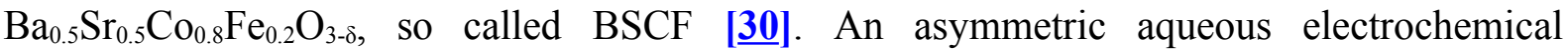
capacitors with a $\mathrm{FeWO}_{4}$ negative electrode material has already been tested using $\mathrm{MnO}_{2}$ as the positive electrode [ $\underline{\mathbf{3 1}}$ ]. This device presents a specific capacitance of $9 \mathrm{~F} \mathrm{~g}^{-1}$ (total weight of both electrodes) at $20 \mathrm{mV} \cdot \mathrm{s}^{-1}$ in $5 \mathrm{M} \mathrm{LiNO}_{3}$ with a high cycling ability over 40,000 cycles. The crystallographic density of $\mathrm{FeWO}_{4}$ and BSCF materials is 7.5 and $5.8{\mathrm{~g} . \mathrm{cm}^{-3}}^{-3}$, respectively, i.e. 6 to 7 times greater than that of standard activated carbon. As such, both materials present high volumetric capacitance in aqueous medium $(5 \mathrm{M} \mathrm{LiNO} 3)$. Furthermore, their respective operational potential windows are complementary $\left(-0.6-0 \mathrm{~V}\right.$ vs $\mathrm{Ag} / \mathrm{AgCl}$ for $\mathrm{FeWO}_{4}$ and $0-$ $0.8 \mathrm{~V}$ vs $\mathrm{Ag} / \mathrm{AgCl}$ for $\mathrm{BSCF})$. Thus, it seems interesting to evaluate the volumetric performance of such electrochemical capacitor devices built from these two electrode materials.

Electrochemical capacitor devices with BSCF positive electrodes have never been reported in the literature. As such, we report hereafter the study of two asymmetric devices: the first one associates an activated carbon electrode with a BSCF electrode $(\mathrm{C} / \mathrm{BSCF})$ and the second one associates $\mathrm{FeWO}_{4}$ and $\mathrm{BSCF}$ electrodes $\left(\mathrm{FeWO}_{4} / \mathrm{BSCF}\right)$. Both devices were operated in aqueous $5 \mathrm{M} \mathrm{LiNO}_{3}$ electrolyte. Several devices have been built and tested to determine the conditions, in terms of electrode weight ratios and current densities, allowing a good 
compromise between performances and electrochemical stability window of each electrode. Specific and volumetric performance and cycling ability of these devices have been evaluated by galvanostatic cycling. Self-discharge measurements have been performed by a chronoamperometry/chronopotentiometry routine. Performance of these devices are commented to argue on the interest of using high density electrode materials to improve the volumetric energy density of electrochemical capacitors.

\section{Experimental section}

\subsection{Materials}

$\mathrm{Ba}_{0.5} \mathrm{Sr}_{0.5} \mathrm{Co}_{0.8} \mathrm{Fe}_{0.2} \mathrm{O}_{3-\delta}-\mathrm{BSCF}$

All precursors were purchased from Sigma Aldrich. Precursors mass used are listed in Tab.S1. BSCF was prepared by a modified glycine-nitrate process. $\mathrm{Ba}\left(\mathrm{NO}_{3}\right)_{2}$ (ACS Reagent, $\geq 99 \%$ ), $\quad \mathrm{Sr}\left(\mathrm{NO}_{3}\right)_{2} \quad$ (ACS Reagent, $\left.\geq 99 \%\right), \mathrm{Co}\left(\mathrm{NO}_{3}\right)_{2}, 6 \mathrm{H}_{2} \mathrm{O}$ (ACS Reagent, $\geq 98 \%$ ) and $\mathrm{Fe}\left(\mathrm{NO}_{3}\right)_{3}, 9 \mathrm{H}_{2} \mathrm{O}$ (ACS Reagent, $\geq 98 \%$ ) were dissolved in stoichiometric quantities in distilled water at $100^{\circ} \mathrm{C}$ and under vigorous stirring. A red solution is obtained. After dissolution, glycine (ACS Reagent, $\geq 98.5 \%$ ), acting as complexing agent and fuel, was added to the solution. Ten minutes after glycine dissolution, ethylenediaminetetraacetique acid EDTA, acting as complexing agent (anhydrous, $\geq 99 \%$ ) was added. The stoichiometry quantities of glycine and EDTA were determined following reactions pathways (1) and (2) respectively:

$$
\begin{gathered}
0.5 \mathrm{Ba}\left(\mathrm{NO}_{3}\right)_{2}+ \\
0.5 \mathrm{Sr}\left(\mathrm{NO}_{3}\right)_{2}+0.8 \mathrm{Co}\left(\mathrm{NO}_{3}\right)_{2}+0.2 \mathrm{Fe}\left(\mathrm{NO}_{3}\right)_{3}+2.13 \mathrm{HOOC}-\mathrm{CH}_{2}-\mathrm{NH}_{2} \\
\mathrm{Ba}_{0.5} \mathrm{Sr}_{0.5} \mathrm{Co}_{0.8} \mathrm{Fe}_{0.2} \mathrm{O}_{3}+4.26 \mathrm{CO}_{2}+5.33 \mathrm{H}_{2} \mathrm{O}+3.165 \mathrm{~N}_{2}
\end{gathered}
$$

$$
\begin{gathered}
0.5 \mathrm{Ba}\left(\mathrm{NO}_{3}\right)_{2}+0.5 \mathrm{Sr}\left(\mathrm{NO}_{3}\right)_{2}+0.8 \mathrm{Co}\left(\mathrm{NO}_{3}\right)_{2}+0.2 \mathrm{Fe}\left(\mathrm{NO}_{3}\right)_{3}+0.48 \mathrm{C}_{10} \mathrm{H}_{16} \mathrm{~N}_{2} \mathrm{O}_{8} \\
\mathrm{Ba}_{0.5} \mathrm{Sr}_{0.5} \mathrm{Co}_{0.8} \mathrm{Fe}_{0.2} \mathrm{O}_{3}+4.8 \mathrm{CO}_{2}+3.84 \mathrm{H}_{2} \mathrm{O}+2.58 \mathrm{~N}_{2}
\end{gathered}
$$


In order to synthesize large amounts of BSCF, expected glycine and EDTA masses were multiplied by 2.5 and 2, respectively. After EDTA dissolution, a $60 \mathrm{~mL}$ purple-black solution is obtained. At the end of the water evaporation (about one hour), the gelification process started. The gel was then transferred in an oven at $600^{\circ} \mathrm{C}$ under air atmosphere where a combustion took place 10 minutes later. Resulting ashes were kept at $600^{\circ} \mathrm{C}$ for one hour to remove carbon residues. Finally, ashes were manually ground and heated at $850^{\circ} \mathrm{C}$ for 10 hours.

$\mathrm{FeWO}_{4}$

$\mathrm{FeWO}_{4}$ was synthesized by a precipitation method. Two equimolar $15 \mathrm{~mL}$ solutions of $\mathrm{FeCl}_{2} \cdot 4 \mathrm{H}_{2} \mathrm{O}$ (puriss. p.a., $\geq 99 \%$ ) and $\mathrm{Na}_{2} \mathrm{WO}_{4} \cdot 2 \mathrm{H}_{2} \mathrm{O}$ (ACS Reagent, $\geq 99 \%$ ), both from Sigma Aldrich were prepared. Precursor mass used are listed in Tab.S2. The iron chloride solution was heated at $70^{\circ} \mathrm{C}$ under magnetic stirring for 10 minutes. Then, the sodium tungstate was added dropwise into the iron chloride solution leading to a brow precipitate. The resulting solution was kept at $70^{\circ} \mathrm{C}$ under magnetic stirring for 3 hours. The precipitate was recovered by filtration before being washed three times with distilled water and subsequently three times with ethanol.

\section{Activated carbon}

Activated carbon was purchased from ACS Material ${ }^{\circledR}$. The particle average size is $5 \mu \mathrm{m}$. Activated carbon from ACS Material ${ }^{\circledR}$ is mesoporous with a pore size distribution from 2 to $2.2 \mathrm{~nm}$ and its BET specific surface area is $2,000 \mathrm{~m}^{2} \cdot \mathrm{g}^{-1}$. 
2.2.BSCF and $\mathrm{FeWO}_{4}$ powder characterizations

Prepared $\mathrm{BSCF}$ and $\mathrm{FeWO}_{4}$ powders were characterized by X-ray diffraction using a PANalytical X'Pert in the Bragg-Brentano configuration with $\mathrm{CuK} \alpha$ radiation, from 10 to $90^{\circ}$ with a step angle of $0.032^{\circ}$. Their morphology were observed by scanning electron microscopy on a Hitachi S4800. BSCF composition was evaluated by EDS analysis.

\subsection{Electrode preparation}

Electrodes were prepared by mixing active materials with acetylene black (Alfa Aesar) and PTFE (60 wt $\%$ dispersed in water, Sigma Aldrich) in ethanol. Mass ratios (active material: acetylene black: PTFE) were 60:30:10 for $\mathrm{BSCF}$ and $\mathrm{FeWO}_{4}$ based electrodes and 75:15:10 for activated carbon based electrodes. After ethanol evaporation at $60^{\circ} \mathrm{C}$ under magnetic stirring, the resulting paste was repeatedly cold rolled until a homogeneous film was obtained. A $10 \mathrm{~mm}$ diameter disk was cut off from the film and pressed at 10 tons onto a folded stainless steel grid. For asymmetric devices (Swagelok type), electrode films were pressed onto nickel foam at 10 tons. Then, a $6 \mathrm{~mm}$ diameter disk shape was cut off. Electrode loadings used for electrochemical tests were 3.2-4.0 $\mathrm{mg}_{\text {carbone. }} . \mathrm{cm}^{-2}\left(5.3-6.7 \mathrm{mg}_{\text {electrode }} . \mathrm{cm}^{-2}\right)$, 4.4$15.3 \mathrm{mg}_{\mathrm{BSCF}} . \mathrm{cm}^{-2}\left(7.4-25.5 \mathrm{mg}_{\text {electrode }} . \mathrm{cm}^{-2}\right)$ and 4.7-5.5 $\mathrm{mg}_{\mathrm{FeWO}} . \mathrm{cm}^{-2}\left(7.8-9.2 \mathrm{mg}_{\text {electrode. }} . \mathrm{cm}^{-2}\right)$.

In contrast with the $20 \mathrm{wt} \%$ usually used, a larger amount of acetylene black was necessary to fabricate $\mathrm{BSCF}$ and $\mathrm{FeWO}_{4}$ electrodes. Only from $30 \mathrm{wt} \%$, a percolation threshold was reached allowing electrodes to have a sufficient electronic conductivity for optimal performances. At lower acetylene black content, the electrochemical signature of electrodes was less capacitive and a specific capacitance twice lower was obtained [ $\underline{\mathbf{3 0}}]$. Furthermore, the specific capacitance of acetylene black in these electrodes is $1 \mathrm{~F} \cdot \mathrm{g}^{-1}$. With respect to the measured electrode capacitances such limited contribution was neglected. 


\subsection{Electrochemical tests}

$\mathrm{BSCF}, \mathrm{FeWO}_{4}$ and activated carbon -based electrodes were first tested in a three electrode cell with a platinum counter electrode and an $\mathrm{Ag} / \mathrm{AgCl}$ reference electrode. Cyclic voltammetry was performed in $5 \mathrm{M} \mathrm{LiNO}_{3}$ at $5 \mathrm{mV} . \mathrm{s}^{-1}$ to determine their potential window and specific capacitance. Specific capacitances $C_{\text {spe,electrode }}\left(\right.$ in $\mathrm{F} . \mathrm{g}^{-1}$ ) are calculated with the following equation:

$$
C_{\text {spe }, \text { electrode }}=\frac{\int_{V_{i}}^{V_{f}} i \cdot d V}{\Delta V \cdot v \cdot m}
$$

With $\int_{V_{i}}^{V_{f}} i . d V$ the voltammogramm positive part area (in A.s), $\Delta V$ the potential window (in V), $v$ the scan rate (in V.s $\mathrm{s}^{-1}$ ) and $m$ the active material mass (in $\mathrm{g}$ ).

Asymmetric $\mathrm{C} / \mathrm{BSCF}$ and $\mathrm{FeWO}_{4} / \mathrm{BSCF}$ device specific and volumetric performance were evaluated by cyclic voltammetry and galvanostatic cycling (in a current density range from

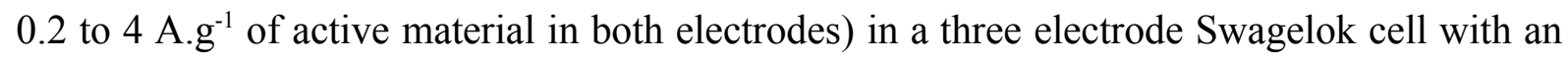
$\mathrm{Ag} / \mathrm{AgCl}$ reference electrode, in aqueous $5 \mathrm{M} \mathrm{LiNO}_{3}$. Both electrodes were separated with glass microfibers separators (Wathman ${ }^{\circledR}$ paper). By cyclic voltammetry, the device capacitances $C$ (in F), specific capacitances $C_{s p e}\left(\right.$ in $\mathrm{F} \cdot \mathrm{g}^{-1}$ ) and volumetric capacitances $C_{v o l}$ (in F.cm ${ }^{-3}$ ) were calculated using equations 4,5 and 6 respectively.

$$
C=\frac{\int_{V_{i}}^{V_{f}} i \cdot d V}{\Delta U \cdot v}
$$




$$
\begin{gathered}
C_{\text {spe }}=\frac{C}{m^{\prime}} \\
C_{v o l}=\frac{C}{V}
\end{gathered}
$$

Where $\Delta U$ is the device cell voltage, in $\mathrm{V}, m^{\prime}$ ' is the active material mass in both electrodes in $\mathrm{g}$ and $\mathrm{V}$ is the geometrical volume of both electrodes and the geometrical volume of both nickel foam current collectors in $\mathrm{cm}^{3}$.

The capacitance $C$, the maximum energy $E_{\max }$ (in $\mathrm{Wh}$ ) and power densities $P_{\max }$ (in W) were calculated from galvanostatic cycling and with equations 7,8 and 9:

$$
\begin{gathered}
C=i \cdot \frac{\int_{t_{i}}^{t_{f}} \Delta U \cdot d t}{\Delta U^{2}} \\
E_{\max }=\frac{1}{2} \cdot C \cdot \Delta U^{2} \\
P_{\max }=\frac{\Delta U^{2}}{4 \cdot R}
\end{gathered}
$$

Where $i$ is the applied current density, $\Delta \mathrm{U}$ is the cell voltage of the device of the device and $R$ is the equivalent series resistance $(\Omega)$ obtained by ohmic drop measurement during galvanostatic cycling. Specific performance (and specific capacitances) were calculated by taking into account the active material mass of both electrodes (Eq. 5). As the specific capacitance of acetylene black used in the electrodes is less than $1 \mathrm{~F}^{-1} \mathrm{~g}^{-1}$, its contribution was neglected. Volumetric performance were obtained by taking into account both electrodes and nickel foam current collector volume (Eq. 6). Self-discharge behaviors were evaluated 
through chronopotentiometry technique. Before this step, devices were fully galvanostatically charged and the cell were kept at their maximum cell voltage during 3 hours before letting the device self-discharged. Cycling ability of $\mathrm{C} / \mathrm{BSCF}$ and $\mathrm{FeWO}_{4} / \mathrm{BSCF}$ devices was evaluated by galvanostatic cycling. All electrochemical tests were performed using a VMP3 potentiostat-galvanostat from Biologic running with the EC-Lab software. A $5 \mathrm{M} \mathrm{LiNO}_{3}$ electrolyte was used as the best specific capacitances for both $\mathrm{BSCF}$ and $\mathrm{FeWO}_{4}$ electrodes were obtained in this given electrolyte.

\section{Results and discussion}

\subsection{BSCF and $\mathrm{FeWO}_{4}$ powder characterizations}

BSCF and $\mathrm{FeWO}_{4}$ XRD patterns are shown in Fig. S1. BSCF XRD pattern is characteristic of a perovskite structure with the expected Pm-3m space group. BSCF XRD pattern is similar to those of previous studies where BSCF was prepared by various sol-gel synthesis [르-36], including the glycine-nitrate process $[\underline{\mathbf{3 2}}]$, and by solid state reaction [ $\underline{\mathbf{3 5}}]$, which all needed a minimum calcination temperature of $900^{\circ} \mathrm{C}$. $\mathrm{FeWO}_{4}$ XRD pattern shows broad peaks of low intensities, characteristic of the poor crystallinity of $\mathrm{FeWO}_{4}$ prepared by precipitation method. $\mathrm{FeWO}_{4} \mathrm{XRD}$ pattern is different of those of $\mathrm{FeWO}_{4}$ prepared by hydrothermal synthesis of polyol-mediated synthesis which allowed to prepare crystalline particles because a minimum annealed temperature of $180^{\circ} \mathrm{C}$ was used $[28,37]$. In our case, the temperature used from the beginning to the end of the synthesis is $70^{\circ} \mathrm{C}$ and the XRD pattern is similar to the one of $\mathrm{NiWO}_{4}$ prepared by the same route [요. EDS analysis of BSCF powder showed that the atomic ratio $\mathrm{Ba} / \mathrm{Sr}$ is close to 1 . Furthermore, the atomic percentage of $\mathrm{Co}$ in the $\mathrm{B}$ site of the perovskite is $80 \%$. Finally, the atomic ratio $(\mathrm{Ba}+\mathrm{Sr}) /(\mathrm{Co}+\mathrm{Fe})$ is close to 1 (see Tab. S3). The overall chemical composition is thus confirmed for the prepared BSCF. SEM pictures of 
BSCF and $\mathrm{FeWO}_{4}$ powders are depicted in Fig. S2. BSCF prepared powder is composed of 5$20 \mu \mathrm{m}$ particles whereas $\mathrm{FeWO}_{4}$ SEM micrography shows that the powder is composed of 20$40 \mathrm{~nm}$ particles.

3.2.Electrochemical tests with $\mathrm{BSCF}, \mathrm{FeWO}_{4}$ and activated carbon electrodes

In Fig. 1 are shown the cyclic voltammograms $(\mathrm{CVs})$ of $\mathrm{BSCF}\left(50^{\text {th }}\right.$ cycle $), \mathrm{FeWO}_{4}\left(10^{\text {th }}\right.$ cycle) and activated carbon $\left(10^{\text {th }}\right.$ cycle) based electrodes, recorded in $5 \mathrm{M} \mathrm{LiNO}_{3}$ at $5 \mathrm{mV} \cdot \mathrm{s}^{-1}$. BSCF CV (Fig. 1a) depicts a box-type shape characteristic of a material with a pseudocapacitive behavior, with some distortions from the typical rectangular shape. BSCF based electrode is stable from 0 to $0.8 \mathrm{~V} v s \mathrm{Ag} / \mathrm{AgCl}$ and displays a specific capacitance of 57 F. $\mathrm{g}^{-1}$ (46 C. $\left.\mathrm{g}^{-1}\right)$. As such, it can be used as positive electrode material. Above 0.8 and below 0 $\mathrm{V}$ vs $\mathrm{Ag} / \mathrm{AgCl}$, the current increases (in absolute value). This is assigned to oxygen and hydrogen evolution reactions, respectively. In the present case, the $50^{\text {th }}$ cycle is the cycle from which the $\mathrm{CV}$ shape and the specific capacitance does not change anymore. From the $1^{\text {st }}$ to the $50^{\text {th }}$ cycle, an increase of the specific capacitance from 30 to $57 \mathrm{~F}^{-1} \mathrm{~g}^{-1}$ was observed. $\mathrm{FeWO}_{4}$ has already been studied as negative electrode material for supercapacitors. The electrode made from $\mathrm{FeWO}_{4}$ prepared by a precipitation method is stable from -0.6 to $0 \mathrm{~V} v s \mathrm{Ag} / \mathrm{AgCl}$ (Fig. 1b) and displays a specific capacitance of $60 \mathrm{~F} \cdot \mathrm{g}^{-1}\left(36 \mathrm{C}^{-1} \mathrm{~g}^{-1}\right)$. Stable CV shape of $\mathrm{FeWO}_{4}$ were rapidly obtained (10 cycles). From the $1^{\text {st }}$ cycle to the $10^{\text {th }}$, only a very slight change in specific capacitance was observed. The charge storage mechanism in $\mathrm{FeWO}_{4}$ electrode involves the $\mathrm{Fe}^{2+} / \mathrm{Fe}^{3+}$ redox couple. Potential below $-0.7 \mathrm{~V}$ vs $\mathrm{Ag} / \mathrm{AgCl}$ should be avoided because $\mathrm{Fe}^{2+}$ is irreversibly reduced to $\mathrm{Fe}^{0}$. $\mathrm{CV}$ of activated carbon (as negative electrode) is representative of a capacitive behavior (Fig. 1c). This electrode can be cycled from -0.8 to $0 \mathrm{~V} v s \mathrm{Ag} / \mathrm{AgCl}$. Below $-0.8 \mathrm{~V}$ vs $\mathrm{Ag} / \mathrm{AgCl}$, the current increases (in absolute 
value), which suggests that the hydrogen evolution reaction begins, causing electrolyte degradation. In this potential window, its specific capacitance is $160{\mathrm{~F} . \mathrm{g}^{-1}}^{\left.-128 \mathrm{C} . \mathrm{g}^{-1}\right) \text { at } 5}$ $\mathrm{mV} . \mathrm{s}^{-1}$. According to these tests, two types of asymmetric devices can be built. The first one, $\mathrm{C} / \mathrm{BSCF}$, is designed by associating a negative electrode made of activated carbon and a BSCF positive electrode. The second one is an all oxide device, with a negative electrode made of $\mathrm{FeWO}_{4}$ and a BSCF positive electrode.

a)

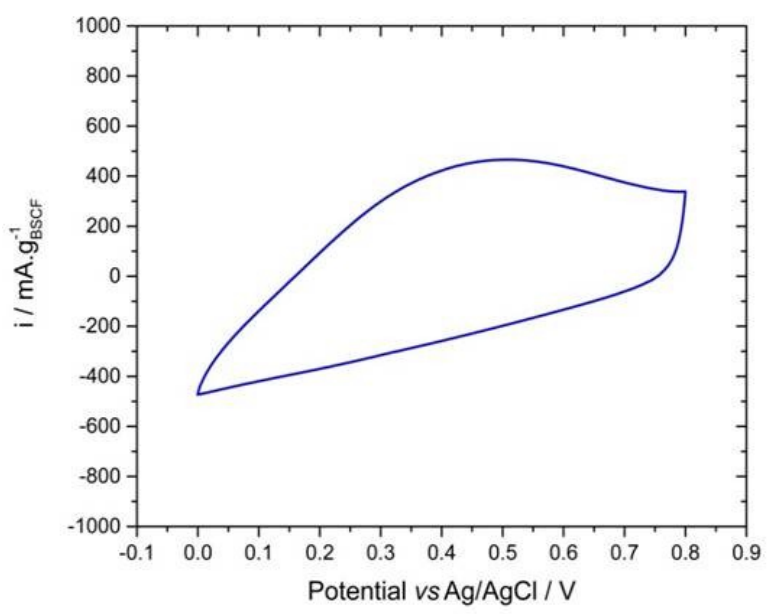

b)

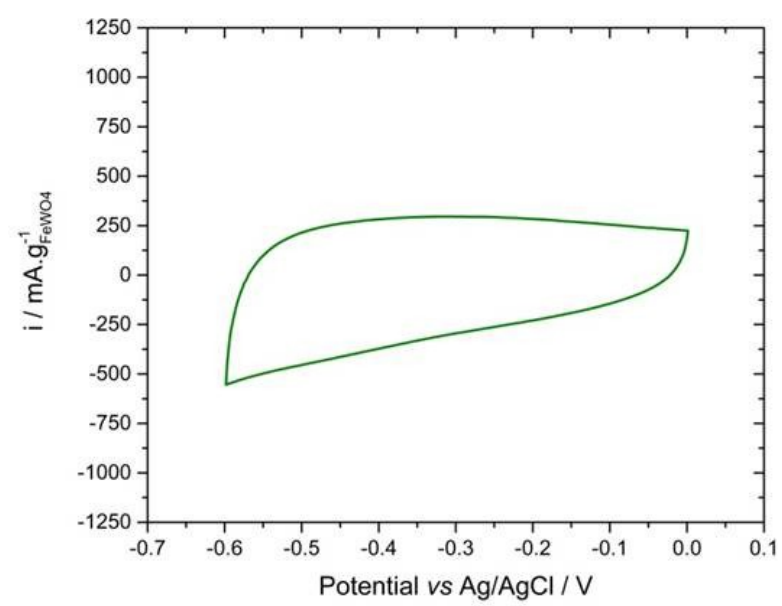

c)

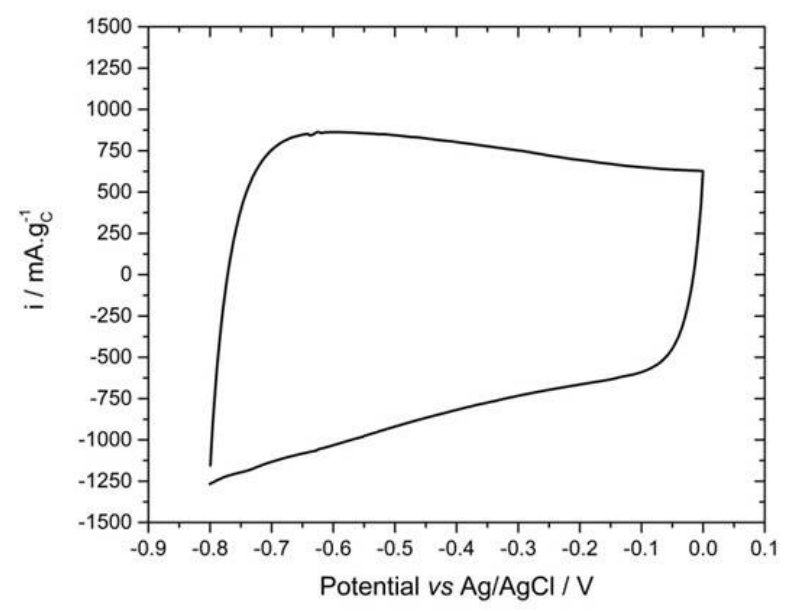

Fig. 1.CVs recorded at $5 \mathrm{mV} \cdot \mathrm{s}^{-1}$ in aqueous $5 \mathrm{M} \mathrm{LiNO}$ of a) $\mathrm{BSCF}$ based electrode $\left(50^{\text {th }}\right.$ cycle $), b) \mathrm{FeWO}_{4}$ based electrode $\left(10^{\text {th }}\right.$ cycle $)$ and c) activated carbon electrode $\left(10^{\text {th }}\right.$ cycle $)$; gravimetric values are expressed per active weight in electrodes. 


\subsection{Asymmetric devices}

To keep electrode cycling in their respective potential windows, charge balance of the device has to be ensured by using an accurate weight ratio of active materials in both electrodes (calculated by taking into account electrode capacities and potential windows) [푸․ However, since each electrode material has different capabilities upon scan rate (or current density), this weight ratio can only be determined for a given scan rate or a given current density. In the next section, the methodology was as followed. Firstly, weight ratios were calculated to design asymmetric devices with the aim to be cycled at $5 \mathrm{mV} \cdot \mathrm{s}^{-1}$ (or corresponding current density) in $5 \mathrm{M} \mathrm{LiNO}_{3}$ electrolyte. These specific ratios were determined using equation (10):

$$
\frac{m^{+i}}{m^{-i}=\frac{C^{-i}}{C^{+i} i} i i} i
$$

Where $\mathrm{m}^{+}$and $\mathrm{m}^{-}$are the active material mass in the positive and the negative electrode respectively and $\mathrm{C}^{+}$and $\mathrm{C}^{-}$are the capacities (in $\mathrm{C}_{\mathrm{g}} \mathrm{g}^{-1}$ ) of the positive and negative electrode respectively.

After analysis of the results (capacitances and electrochemical stability windows of electrodes), several devices with various electrode weight ratios were designed and tested by galvanostatic cycling at various current densities with the aim to find the optimal conditions allowing a good compromise between the device performances and the electrochemical stability windows of each electrodes. In this section, from one weight ratio to another, performances are not compared at the same current density, but in conditions electrodes cycle in their respective electrochemical stability window (i.e. in conditions a fast degradation of the device, caused by water splitting, is avoided). The conditions, in terms of electrode weight 
ratios and current densities, leading to the best compromise between electrochemical stability of electrodes and performances, were used to test the longterm cycling ability and selfdischarge behavior of the fabricated asymmetric devices.

\subsubsection{Asymmetric C/BSCF devices}

As mentioned in paragraph 3.2., specific capacities of BSCF and activated carbon (as negative electrode) in $5 \mathrm{M} \mathrm{LiNO}_{3}$ at $5 \mathrm{mV} \cdot \mathrm{s}^{-1}$ are 46 and $128 \mathrm{C} \cdot \mathrm{g}^{-1}$, respectively. Thus, a theoretical $\mathrm{BSCF} / \mathrm{C}$ weight ratio of 2.8 is expected to allow the electrodes to cycle in their respective stable potential windows (i.e. from 0 to $0.8 \mathrm{~V} v s \mathrm{Ag} / \mathrm{AgCl}$ for $\mathrm{BSCF}$ and from -0.8 to $0 \mathrm{~V} v s$ $\mathrm{Ag} / \mathrm{AgCl}$ for activated carbon). As such, electrode loadings used to build this device with a

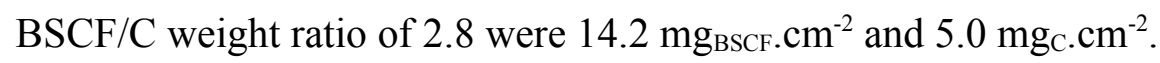

Fig. S3 depicts $\mathrm{C} / \mathrm{BSCF} \mathrm{CV}$ from 0 to $1.6 \mathrm{~V}$ (according to the electrochemical window of each electrodes), together with those of activated carbon and BSCF electrodes. The CV shape of the full device is rectangular as expected for an electrochemical capacitor. However, as shown in Fig. S3, activated carbon and BSCF do not cycle in their respective electrochemical window. In such a case, potential windows of activated carbon and BSCF based electrodes are $-1.0--0.1 \mathrm{~V}$ vs $\mathrm{Ag} / \mathrm{AgCl}$ and $-0.1-0.6 \mathrm{~V}$ vs $\mathrm{Ag} / \mathrm{AgCl}$, respectively. As mentioned above, at $1.0 \mathrm{~V}$ vs $\mathrm{Ag} / \mathrm{AgCl}$, water is reduced at the carbon electrode surface and loss of performance upon cycling the cell is likely to occur because of this electrolyte degradation. Actually, the same shift in the electrode potential windows was observed when using a current density

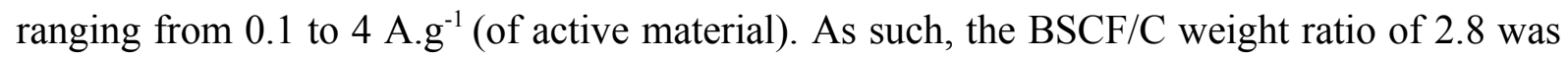
no longer considered for the rest of the study.

To evaluate $\mathrm{C} / \mathrm{BSCF}$ performance, several devices with various $\mathrm{BSCF} / \mathrm{C}$ weight ratio have then been prepared and tested. $\mathrm{BSCF} / \mathrm{C}$ weight ratio were $1.5,2.1,2.4$ and 3.6. CVs at $5 \mathrm{mV} . \mathrm{s}^{-}$ 
${ }^{1}$ of the fabricated devices are reported in Fig. S4. Total mass of active material and total volume of electrodes and current collectors used to evaluate device performance are listed in Tab. S4 together with the capacitances and the specific capacitances. Despite a slight decrease for the weight ratio of 3.6, the greater the weight ratio, the greater the measured capacitance. In contrast, the greater electrode masses needed for the highest weight ratio strongly impacted on the corresponding specific capacitances, as the greater the weight ratio, the lower the specific capacitance. Looking closer at electrode CVs in Fig. S4, one can notice that electrodes were operated in their safe electrochemical window only for the device with a weight ratio of 1.5 , i.e. between 0 and $-0.8 \mathrm{~V} v s \mathrm{Ag} / \mathrm{AgCl}$ for activated carbon electrode and between 0 and $+0.8 \mathrm{~V}$ vs $\mathrm{Ag} / \mathrm{AgCl}$ for $\mathrm{BSCF}$ electrode. For the other devices, the activated carbon electrode potential window decreases down to $-0.8 \mathrm{~V} v s \mathrm{Ag} / \mathrm{AgCl}$ (hence, $\mathrm{BSCF}$ electrode potential window does not reach $+0.8 \mathrm{~V}$ vs $\mathrm{Ag} / \mathrm{AgCl}$ ) which could lead to electrolyte degradation.

Energy and power densities of these devices have been determined from galvanostatic cycling

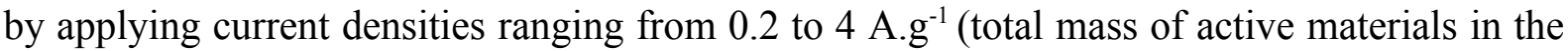
cell). Specific and volumetric performance are shown in Fig. 2a and 2b, respectively, as well as the Ragone plots. The corresponding galvanostatic cycles are depicted in Fig. S5. As generally observed for electrochemical capacitors, the energy density of fabricated $\mathrm{C} / \mathrm{BSCF}$ devices decreased as the applied current density increased. At low current density, i.e. 0.2 A.g1, the greater the $\mathrm{BSCF} / \mathrm{C}$ weight ratio, the lower the energy and the power densities (both specific and volumetric). This behavior was assigned to both lower capacitances and greater

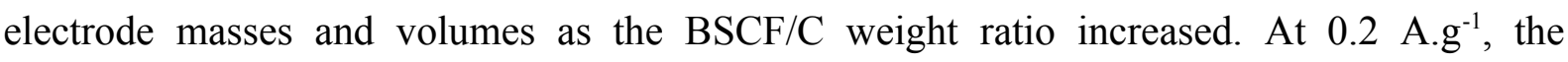
$\mathrm{C} / \mathrm{BSCF}$ device with a weight ratio of 1.5 presented the greatest energy densities in the series at $8.6 \mathrm{Wh} . \mathrm{kg}^{-1}$ and 2.7 Wh.L $\mathrm{L}^{-1}$. A similar trend was observed for power densities. At $0.2 \mathrm{~A} . \mathrm{g}^{-1}$, power densities ranged from 5.6 to $3 \mathrm{~kW} \cdot \mathrm{kg}^{-1}$ and from 1.8 to $1.4 \mathrm{~kW} . \mathrm{L}^{-1}$, depending on the 
$\mathrm{BSCF} / \mathrm{C}$ weight ratio. With the increase of the current density at $4 \mathrm{~A} \cdot \mathrm{g}^{-1}$, the C/BSCF device with a weight ratio of 2.1 showed the greatest energy densities with $3.7 \mathrm{Wh}^{\mathrm{kg}} \mathrm{kg}^{-1}$ and 1.3 Wh. $L^{-1}$. Compared to the device with a 1.5 weight ratio, this energy density improvement originated from a greater capacitance ( $37 \mathrm{mF}$ for a ratio of $2.1 \mathrm{vs} 27 \mathrm{mF}$ for a ratio of 1.5) which allowed to compensate for the larger mass and volume of the electrodes. However,

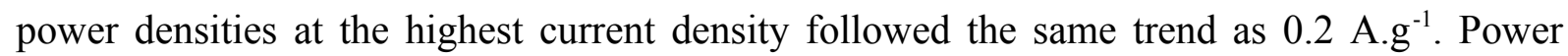

a)

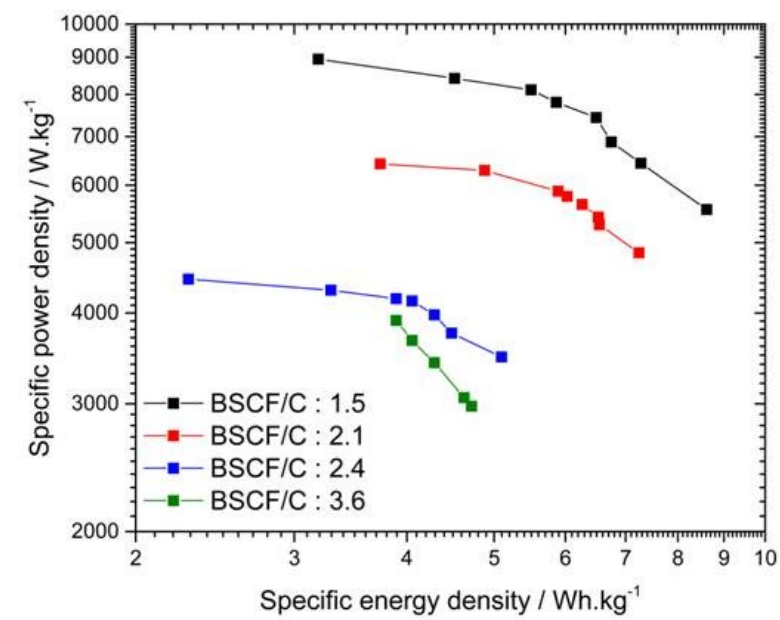

b)

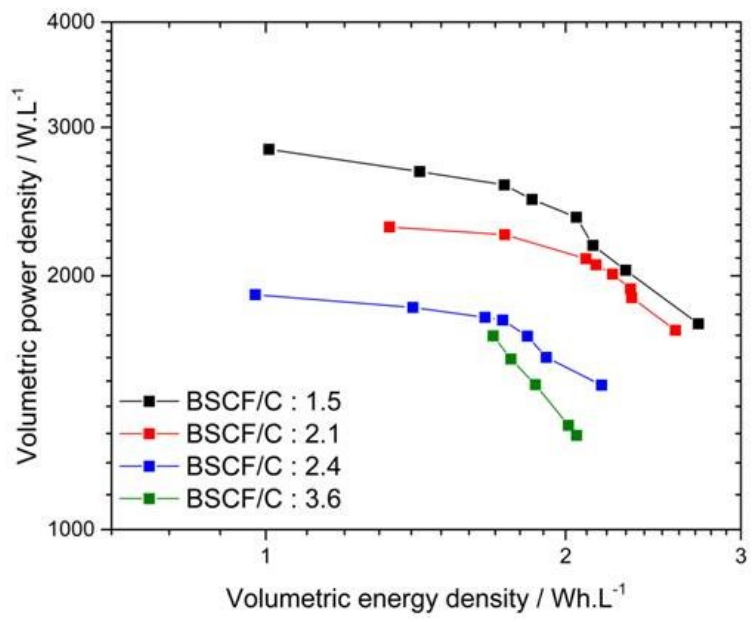

densities decreased from 8.9 to $4.4 \mathrm{Wh} . \mathrm{kg}^{-1}$ and from 2.8 to $1.9 \mathrm{Wh} . \mathrm{L}^{-1}$ when the weight ratio increases.

Fig. 2. Ragone plots representing the evolution of the power density $v s$ the energy density of the four $\mathrm{C} / \mathrm{BSCF}$ devices tested in $5 \mathrm{M} \mathrm{LiNO}_{3}$ with $\mathrm{BSCF} / \mathrm{C}$ ratios of 1.5 (black), 2.1 (red), 2.4 (blue) and 3.6 (green). Current densities applied are 0.2, 0.5, 0.6, 0.8, 1.0, 1.2, 2.0 and 4 A.g . $^{-1}$. Graph a) specific power and energy densities and b) volumetric power and energy densities; gravimetric values are expressed per total active weights in both electrodes and volumetric values per volume of both electrodes and their current collector. Calculations have been done using Eqs (9) and (10).

In the whole range of applied current densities, only a single current density applied for each $\mathrm{C} / \mathrm{BSCF}$ device allows to operate BSCF and $\mathrm{C}$ electrodes in their safe electrochemical

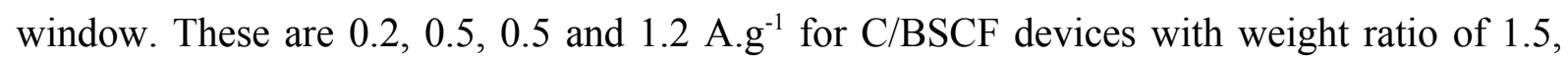
2.1, 2.4 and 3.6, respectively. Respective galvanostatic cycles at such current densities are shown in Fig. S6 and corresponding performance are reported in Tab. 1. Potential ranges of 
activated carbon and BSCF electrodes at such optimized current densities are $-0.8-0 \mathrm{~V} v s$ $\mathrm{Ag} / \mathrm{AgCl}$ and $0-0.8 \mathrm{~V}$ vs $\mathrm{Ag} / \mathrm{AgCl}$, respectively, corresponding to targeted electrochemical stability windows of both electrodes. For lower current densities, activated carbon electrode potential goes below $-0.8 \mathrm{~V} v s \mathrm{Ag} / \mathrm{AgCl}$ and for higher current densities, BSCF electrode potential rises to $0.8 \mathrm{~V}$ vs $\mathrm{Ag} / \mathrm{AgCl}$ and above. According to Tab. 1, increasing the $\mathrm{BSCF} / \mathrm{C}$ weight ratio allows to reach greater charge and discharge rates. To fabricate the most

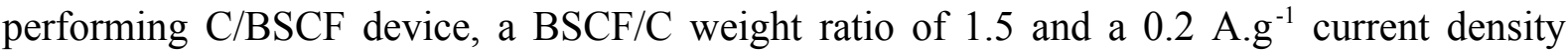
should be considered. However, in these conditions, a large discrepancy between charge and discharge times is observed. To avoid this unbalanced characteristic, the device with a weight ratio of 2.1 operated at a current density of $0.5 \mathrm{~A} \cdot \mathrm{g}^{-1}$ was selected for further tests. To move a step forward in the device characterization, self-discharge measurements and cycling ability

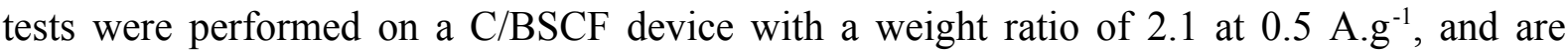
presented in section 3.3.3.

Tab. 1.Specific energy and power densities $\left(\mathrm{E}_{\mathrm{spe}}\right.$ and $\left.\mathrm{P}_{\mathrm{spe}}\right)$, volumetric energy and power densities $\left(\mathrm{E}_{\mathrm{vol}}\right.$ and $\left.\mathrm{P}_{\mathrm{vol}}\right)$ of $\mathrm{C} / \mathrm{BSCF}$ full devices with $\mathrm{BSCF} / \mathrm{C}$ weight ratio of 1.5, 2.1, 2.4 and

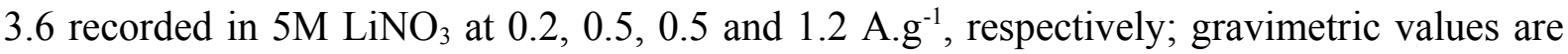
expressed per total active weights in both electrodes and volumetric values per volume of both electrodes and their current collector.

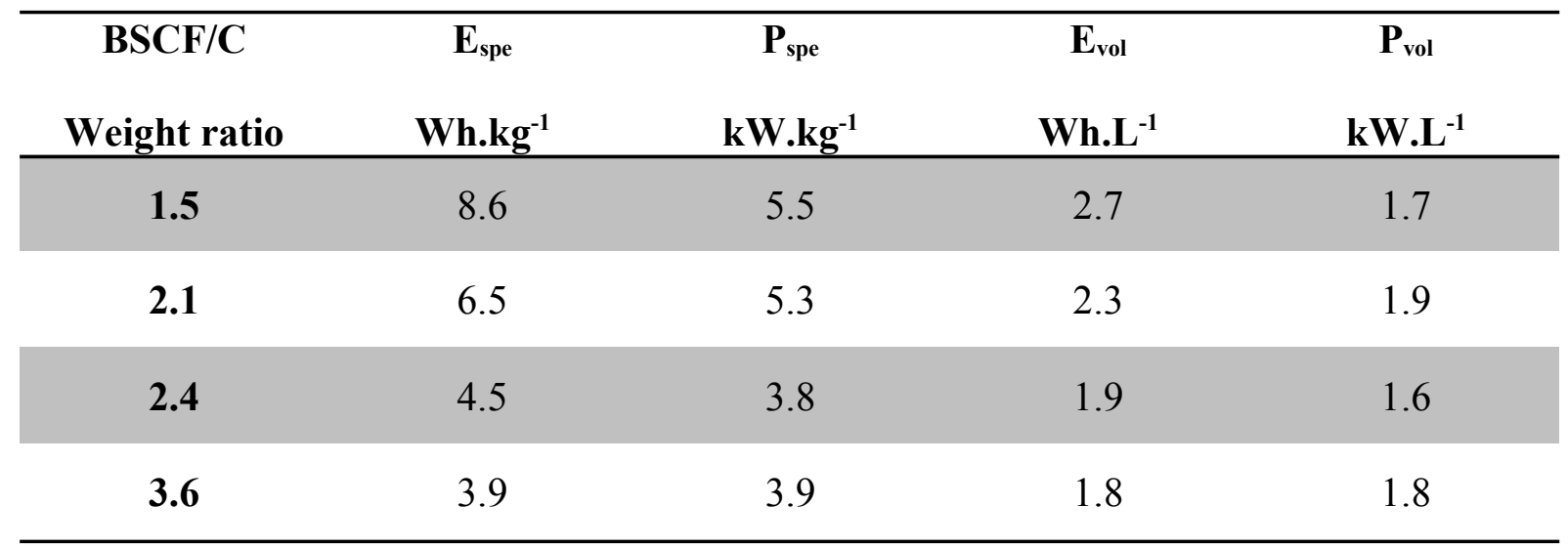




\subsubsection{Asymmetric $\mathrm{FeWO}_{4} / \mathrm{BSCF}$ devices}

The study on all oxide asymmetric $\mathrm{FeWO}_{4} / \mathrm{BSCF}$ devices followed the same methodology as for $\mathrm{C} / \mathrm{BSCF}$ devices. According to specific capacities measured for $\mathrm{FeWO}_{4}$ and $\mathrm{BSCF}$ electrodes, respectively 36 and $46 \mathrm{C} \cdot \mathrm{g}^{-1}$ at $5 \mathrm{mV} \cdot \mathrm{s}^{-1}$ in $5 \mathrm{M} \mathrm{LiNO}_{3}$, a FeWO $4 / \mathrm{BSCF}$ weight ratio of 0.8 should lead to suitable potential windows for both electrodes. Alternatively, two other devices with $\mathrm{FeWO}_{4} / \mathrm{BSCF}$ weight ratio at 1.67 and 2 were tested. These devices have been cycled between 0 and $1.4 \mathrm{~V}$.

$\mathrm{CVs}$ of the various $\mathrm{FeWO}_{4} / \mathrm{BSCF}$ device, together with those of their electrodes, are shown in Fig. 3. Total active material mass, total volume of electrodes and current collectors, capacitances and specific capacitances of fabricated devices are listed in Tab. S5. As for $\mathrm{C} / \mathrm{BSCF}$ devices, the $\mathrm{CV}$ of $\mathrm{FeWO}_{4} / \mathrm{BSCF}$ device shows a distorted rectangular shape, characteristic of a pseudocapacitive behavior. From $\mathrm{FeWO}_{4} / \mathrm{BSCF}$ weight ratio at 0.8 to 2, specific capacitances are found to remain the same, close to $16-17 \mathrm{~F} \cdot \mathrm{g}^{-1}$. The potential window of $\mathrm{BSCF}$ electrode, ranging approximately from $0-0.7 \mathrm{~V} v s \mathrm{Ag} / \mathrm{AgCl}$, was fitting in its electrochemical stability window $(0-0.8 \mathrm{~V} v s \mathrm{Ag} / \mathrm{AgCl})$. However, the potential window of $\mathrm{FeWO}_{4}$ electrodes ranged approximately from $-0.7-0 \mathrm{~V} v s \mathrm{Ag} / \mathrm{AgCl}$. This potential window could result in a fade of performance upon cycling since, at the lowest limit, the electrode potential is very close to that of the irreversible $\mathrm{Fe}^{2+} \rightarrow \mathrm{Fe}^{0}$ reduction reaction. 
a)

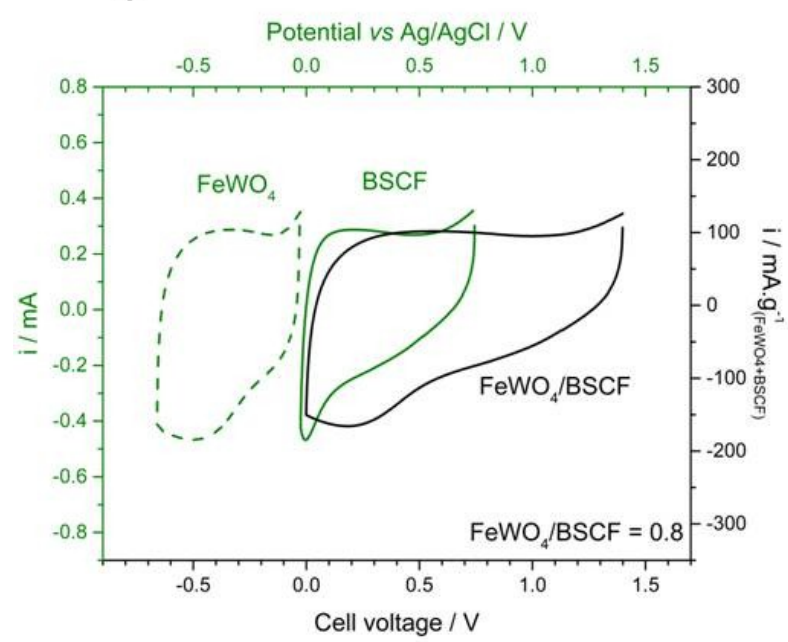

b)

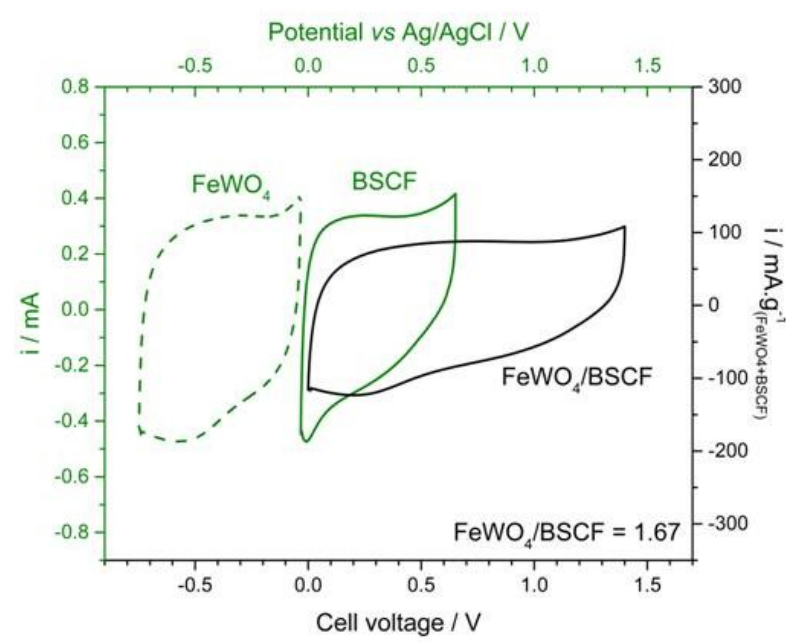

c)

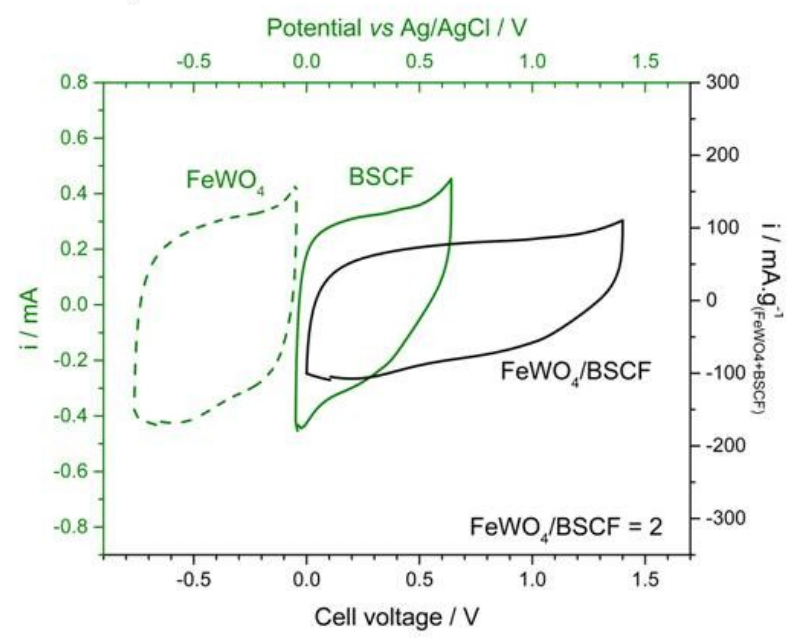

Fig. 3. CVs recorded at $5 \mathrm{mV} \cdot \mathrm{s}^{-1}$ in $5 \mathrm{M} \mathrm{LiNO}_{3}$ of $\mathrm{FeWO}_{4} / \mathrm{BSCF}$ devices (black line) together with $\mathrm{FeWO}_{4}$ (green dots) and BSCF electrodes (green line) $\mathrm{CVs}$ with $\mathrm{BSCF} / \mathrm{FeWO}$ weight ratio of a) 0.8, b) 1.67 and c) 2 ; gravimetric values are expressed per active weight in both electrodes.

To optimize the operating conditions for $\mathrm{FeWO}_{4} / \mathrm{BSCF}$ devices and to evaluate their performance, galvanostatic cycling was performed at various current densities from 0.25 to 4 A.g ${ }^{-1}$. Specific and volumetric densities are reported in Fig. 4 and the galvanostatic cycles are depicted in Fig. S7. Performance of the $\mathrm{FeWO}_{4} / \mathrm{BSCF}$ device with a weight ratio of 0.8 are not reported because, whatever the applied current density, the $\mathrm{FeWO}_{4}$ electrode potential always reached potentials below $-0.7 \mathrm{~V} v s \mathrm{Ag} / \mathrm{AgCl}$. As such, poor coulombic efficiencies at

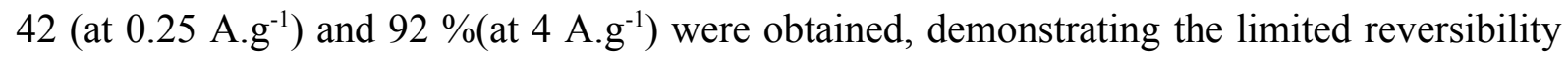


of charge and discharge processes that could originate from an irreversible reduction of $\mathrm{Fe}^{2+}$ to $\mathrm{Fe}^{0}$. As for $\mathrm{C} / \mathrm{BSCF}$ devices, when the current density was greater, the corresponding energy density of $\mathrm{FeWO}_{4} / \mathrm{BSCF}$ devices decreased, either with $\mathrm{FeWO}_{4} / \mathrm{BSCF}$ weight ratio at 1.67 or 2 . Specific and volumetric performance of the tested $\mathrm{FeWO}_{4} / \mathrm{BSCF}$ devices were approximately the same but energy densities of the device with a weight ratio of 2 were slightly weaker. At $0.25 \mathrm{~A} . \mathrm{g}^{-1}$, energy densities of $\mathrm{FeWO}_{4} / \mathrm{BSCF}$ devices with a ratio of 1.67 and 2 were 2.9 and $2.7 \mathrm{Wh} . \mathrm{kg}^{-1}$ respectively, and 1.2 and $1.1 \mathrm{Wh} . \mathrm{L}^{-1}$ respectively. At the same current density, power densities for both devices were similar at about $3.8 \mathrm{~kW} \cdot \mathrm{kg}^{-1}$ and 1.5 $\mathrm{kW} \cdot \mathrm{L}^{-1}$. When the current density is increased to $4 \mathrm{~A} \cdot \mathrm{g}^{-1}$, energy densities of the devices with a ratio of 1.67 and 2 decreased to 1.1 and $1.0 \mathrm{Wh} . \mathrm{kg}^{-1}$, respectively and to 0.5 and $0.4 \mathrm{Wh} . \mathrm{L}^{-1}$, respectively. With these asymmetric devices, the limit of the $\mathrm{FeWO}_{4}$ electrode potential window was lower than the expected value at $-0.6 \mathrm{~V}$ vs $\mathrm{Ag} / \mathrm{AgCl}$. For each devices, a single current density allowed to limit the $\mathrm{FeWO}_{4}$ electrode potential above $-0.7 \mathrm{~V} v s \mathrm{Ag} / \mathrm{AgCl}$, thus limiting the $\mathrm{Fe}^{2+}$ reduction to $\mathrm{Fe}^{0}$. These current densities are 0.4 and $0.25 \mathrm{~A}^{-1} \mathrm{~g}^{-1}$ of active material for $\mathrm{FeWO}_{4} / \mathrm{BSCF}$ devices with weight ratio of 1.67 and 2, respectively (corresponding galvanostatic cycles are in Fig. S8). At such current densities, the devices showed the same energy densities of $2.7 \mathrm{Wh} . \mathrm{kg}^{-1}$ and $1.1 \mathrm{Wh} . \mathrm{L}^{-1}$. The $\mathrm{FeWO}_{4} / \mathrm{BSCF}$ cycling ability and self-discharge behavior were further evaluated on the device with a $\mathrm{FeWO}_{4} / \mathrm{BSCF}$ weight ratio of 2 operated at $0.25 \mathrm{~A} \cdot \mathrm{g}^{-1}$. 
a)

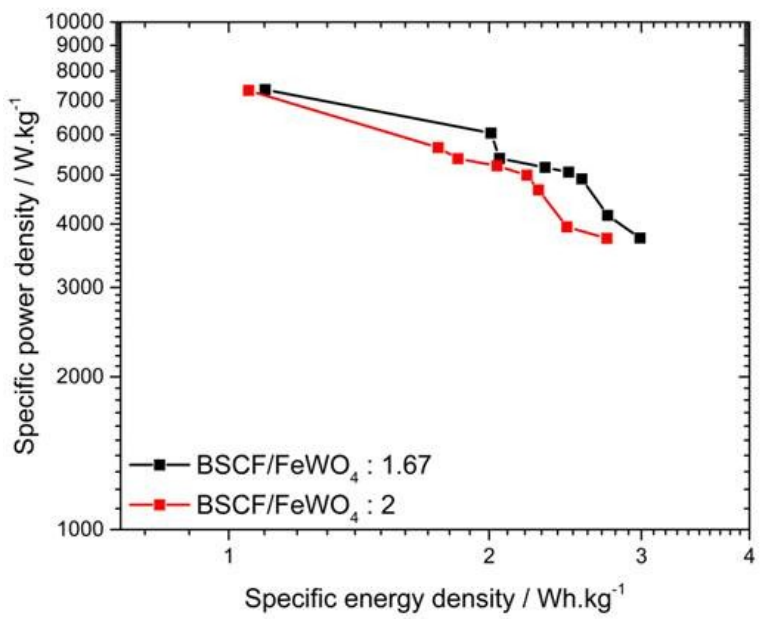

b)

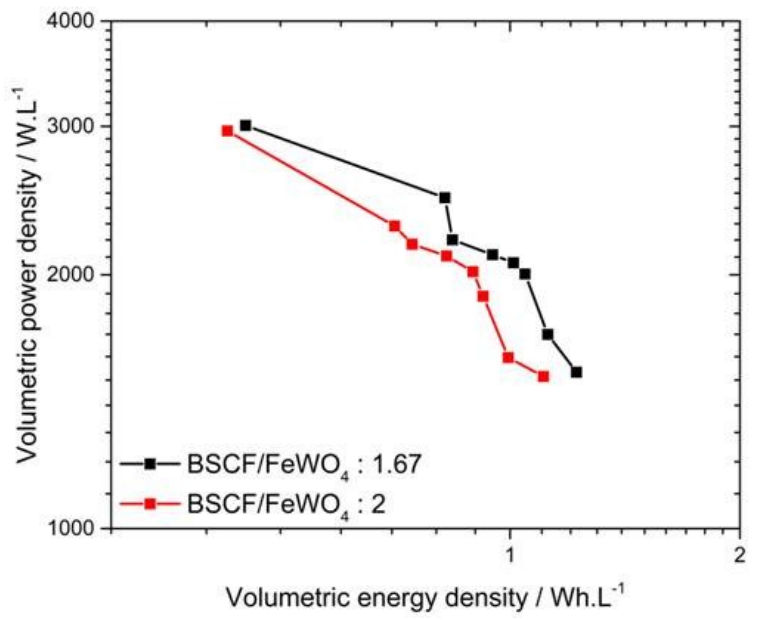

Fig. 4.Ragone plots representing the evolution of the power density $v s$ the energy density of the two $\mathrm{FeWO}_{4} / \mathrm{BSCF}$ devices tested in $5 \mathrm{M} \mathrm{LiNO}_{3}$ with $\mathrm{BSCF} / \mathrm{FeWO}_{4}$ ratio of 1.67 (black) and 2 (red). Current densities applied are $0.25,0.4,0.5,0.6,0.8,1,1.2$ and 4 A.g ${ }^{-1}$. Graph a) represents specific power and energy densities and b) represents volumetric power and energy densities; gravimetric values are expressed per total active weights in both electrodes and volumetric values per volume of both electrodes and their current collector. Calculations have been done using Eqs (9) and (10).

3.3.3. Cycling ability and self-discharge behavior of $\mathrm{C} / \mathrm{BSCF}$ and $\mathrm{FeWO}_{4} / \mathrm{BSCF}$ asymmetric devices

Cycling ability of $\mathrm{C} / \mathrm{BSCF}(\mathrm{BSCF} / \mathrm{C}$ weight ratio of 2.1$)$ and $\mathrm{FeWO}_{4} / \mathrm{BSCF}\left(\mathrm{FeWO}_{4} / \mathrm{BSCF}\right.$

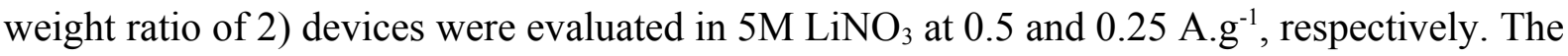
current densities were chosen according to balance the potential window of their electrodes. Evolutions of the specific capacitance of these devices vs number of cycles are depicted in Fig. 5. The specific capacitance of the C/BSCF device was $17 \mathrm{~F}^{-1} \mathrm{~g}^{-1}$ at the beginning of the cycling test, as shown in Fig. 5a. First, the specific capacitance increases which is due to BSCF electrode activation. Then, it progressively decreased down to $15 \mathrm{~F}^{-\mathrm{g}^{-1}}$ for the $10,000^{\text {th }}$ cycle for an overall $12 \%$ fading. This capacitance fading of the device could be due to the BSCF electrode behavior, as it showed a specific capacitance fading of approximately $10 \%$ over 2,000 cycles [ $\underline{\mathbf{3 0}}$, whereas activated carbon electrodes are known to be stable over 
hundred thousands of cycles, eventually. Furthermore, coulombic efficiency of the device was above $98 \%$ over the entire cycling test, demonstrating the good charge/discharge reversibility of the device. To go further, impedance spectroscopy was performed after the $10^{\text {th }}$ and the last cycle of the long term cycling test. Corresponding Nyquist diagrams are shown in Fig. S9a. The resistance measured at high frequencies, at the intercept between the EIS plot and the Z' axis, corresponds to the resistance of the separators impregnated by the electrolyte. This resistance is approximately $1 \Omega$ after the $10^{\text {th }}$ cycle and does not seem to further increase after the $10,000^{\text {th }}$ cycle. At lower frequencies a semi-circle can be observed. It is usually assigned to the interface resistance between the active material and current collector [풍. This charge transfer resistance $(0.8 \Omega)$ showed limited changes upon cycling. It only increased up to $1 \Omega$ from the $10^{\text {th }}$ to the $10,000^{\text {th }}$ cycle. The equivalent series resistance evaluated at high frequency was $2.7 \Omega$ after 10 cycles and increased at $3 \Omega$ after 10,000 cycles. The limited changes upon cycling of the various resistances measured demonstrate the high stability of the device.

Cycling ability of the $\mathrm{FeWO}_{4} / \mathrm{BSCF}$ device has been evaluated over 45,000 cycles. The choice to apply for a greater number of cycles for this specific device was motivated by the opportunity to evaluate the cycling ability of an all-oxide device as only a few studies depict such performance over such a large number of cycles. Changes in the specific capacitance of

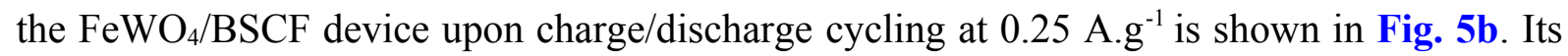
initial specific capacitance at $12 \mathrm{~F}^{-1} \mathrm{~g}^{-1}$ goes down to $10 \mathrm{~F} \cdot \mathrm{g}^{-1}$ at the end of the cycling test, corresponding to an overall $17 \%$ fading of the specific capacitance after 45,000 cycles. In comparison with the $\mathrm{C} / \mathrm{BSCF}$ device, operated at $0.5 \mathrm{~A}_{\mathrm{g}} \mathrm{g}^{-1}$, the specific capacitance fading of the $\mathrm{FeWO}_{4} / \mathrm{BSCF}$ device is limited to about $3 \%$ after the $10,000^{\text {th }}$ cycle, demonstrating the remarkable cycling ability of this device, especially when operated at a moderate current density of $0.25 \mathrm{~A} \cdot \mathrm{g}^{-1}$. As it can be observed on this graph, the capacitance fading is more 
pronounced after 22,000 cycles. This behavior is not necessarily assigned to the electrodes but to a non-optimized setup. The Coulombic efficiency of this device upon the entire cycling test is about $95 \%$, lower than for $\mathrm{C} / \mathrm{BSCF}$ or what is generally observed in electrochemical capacitors $(98-99 \%)$. This can be due to some parasitic $\mathrm{Fe}^{2+}$ reduction reaction to $\mathrm{Fe}^{0}$ because of a potential limit of $\mathrm{FeWO}_{4}$ electrode close to $-0.7 \mathrm{~V} v \mathrm{Ag} / \mathrm{AgCl}$. Nyquist diagrams after 10 cycles and 45,000 cycles are depicted in Fig. S9b. The resistance measured at high frequencies increased from 1.3 to $1.7 \Omega$ after the $45,000^{\text {th }}$ cycle. The semi-circle assigned to the charge transfer resistance is not clearly defined after 45,000 cycles, but, it is clear that this resistance was increased upon cycling. Finally, the equivalent series resistance also increased during cycling, from 7.4 to $18.3 \Omega$.

In the literature, only a few studies deal with long term stability evaluation of symmetric or asymmetric aqueous devices with at least one pseudocapacitive oxide. Among them, asymmetric devices were reported with a negative activated carbon electrode such as $\mathrm{C} / \mathrm{BiMn}_{2} \mathrm{O}_{5}$ [41] and $\mathrm{C} / \mathrm{MnO}_{2}$ [42]. The first one presented only a $90 \%$ retention of its capacitance over 1,000 cycles $\left(10 \mathrm{~mA} . \mathrm{cm}^{-2}, 1.8 \mathrm{~V}, 0.5 \mathrm{M} \mathrm{Na}_{2} \mathrm{SO}_{4}\right)$. On the other hand, the $\mathrm{C} / \mathrm{MnO}_{2}$ device presented the greatest cycling ability ever reported in the literature with a $87.5 \%$ of retention over 195,000 cycles $\left(40 \mathrm{~mA} . \mathrm{cm}^{-2}, 2 \mathrm{~V}, 0.1 \mathrm{M} \mathrm{K}_{2} \mathrm{SO}_{4}\right)$. Some symmetric devices have also been tested, such as $\mathrm{ZnFe}_{2} \mathrm{O}_{4} / \mathrm{ZnFe}_{2} \mathrm{O}_{4}$ (composite electrodes with carbon nanotubes) which maintained only $70 \%$ of its capacitance over 2,000 cycles $(0.9 \mathrm{~V}, 1 \mathrm{M} \mathrm{LiCl})$ [43]. Finally, a few studies on asymmetric devices free of activated carbon have been reported. For example, $\mathrm{VN} / \mathrm{MnO}_{2}$ (composite electrodes with carbon nanotubes) retained only $80 \%$ of its initial capacitance over 1,000 cycles $\left(10 \mathrm{~mA}, 1.8 \mathrm{~V}, 0.5 \mathrm{M} \mathrm{Na}_{2} \mathrm{SO}_{4}\right)$ [44]. The first asymmetric device with two oxides ever reported, $\mathrm{Fe}_{3} \mathrm{O}_{4} / \mathrm{MnO}_{2}$, presented also a limited cycling ability with a $50 \%$ capacitance fading over 5,000 cycles $\left(1.8 \mathrm{~V}, 0.1 \mathrm{M} \mathrm{K}_{2} \mathrm{SO}_{4}\right)$ [ㄴ5] . As a comparison with this latter device, $\mathrm{FeWO}_{4} / \mathrm{MnO}_{2}$ device had a $84 \%$ retention over 40,000 
cycles $\left(20 \mathrm{mV}^{-1}{ }^{-1}, 1.6 \mathrm{~V}, 5 \mathrm{M} \mathrm{LiNO}_{3}\right)[\underline{\mathbf{3 1}}]$. As $\mathrm{MnO}_{2}$ electrode has demonstrated a fair cycling stability, the greater cycling ability of the $\mathrm{FeWO}_{4} / \mathrm{MnO}_{2}$ device when compared to that of $\mathrm{Fe}_{3} \mathrm{O}_{4} / \mathrm{MnO}_{2}$ device was assigned to the stability of the $\mathrm{Fe}^{2+} / \mathrm{Fe}^{3+}$ redox couple in the $\mathrm{FeWO}_{4}$ structure. Initial C/BSCF device capacitance faded down by $12 \%$ over 10,000 cycles $\left(0.5 \mathrm{~A} . \mathrm{g}^{-}\right.$ ${ }^{1}, 1.6 \mathrm{~V}, 5 \mathrm{M} \mathrm{LiNO}{ }_{3}$ ) while it was $17 \%$ fading for the $\mathrm{FeWO}_{4} / \mathrm{BSCF}$ device over 45,000 cycles (0.25 A.g ${ }^{-1}, 1.4 \mathrm{~V}, 5 \mathrm{M} \mathrm{LiNO} 3$ ). This cycling ability, similar to that of $\mathrm{FeWO}_{4} / \mathrm{MnO}_{2}$,

a)

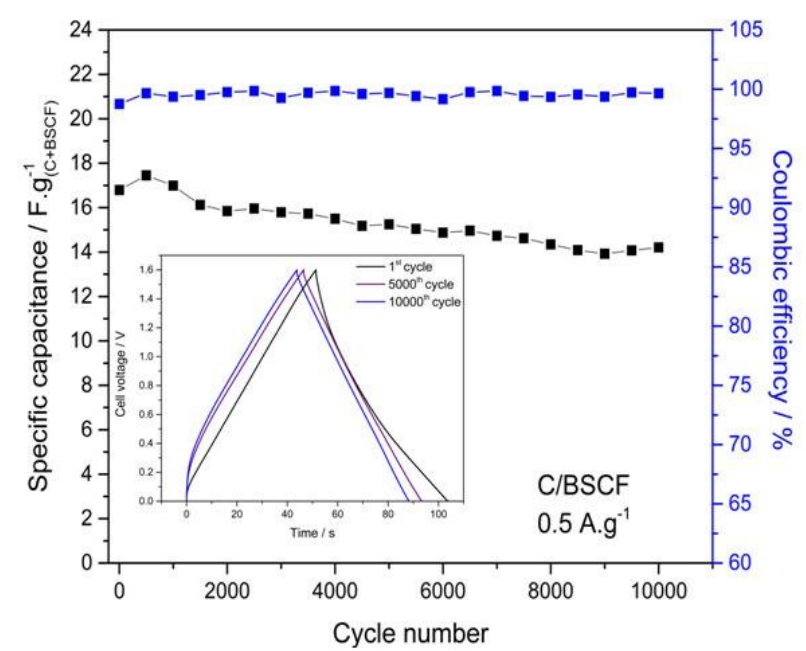

b)

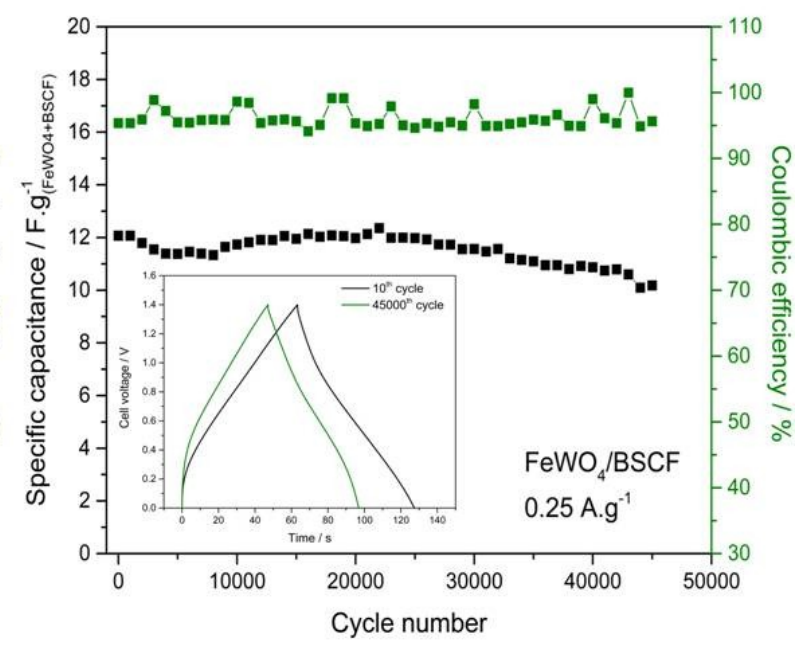

originates from the good cycling stability of individual electrodes.

Fig. 5. Cycling ability test performed on a) $\mathrm{C} / \mathrm{BSCF}$ device with a $\mathrm{BSCF} / \mathrm{C}$ ratio of 2.1 at 0.5 A. ${ }^{-1}$ in $5 \mathrm{M} \mathrm{LiNO}_{3}$ (evolution of the specific capacitance in black and coulombic efficiency in blue) and b) $\mathrm{FeWO}_{4} / \mathrm{BSCF}$ device with a $\mathrm{BSCF} / \mathrm{FeWO}_{4}$ weight ratio of 2 at $0.25 \mathrm{~A}^{-g^{-1}}$ in $5 \mathrm{M}$ $\mathrm{LiNO}_{3}$ (evolution of the specific capacitance in black and coulombic efficiency in green). Insets are galvanostatic cycles after various cycles; gravimetric values are expressed per total active weights in both electrodes.

Self-discharge behavior has been evaluated for $\mathrm{C} / \mathrm{BSCF}$ (BSCF/C weight ratio of 2.1) and $\mathrm{FeWO}_{4} / \mathrm{BSCF}\left(\mathrm{FeWO}_{4} / \mathrm{BSCF}\right.$ weight ratio of 2$)$ devices and compared to that of a symmetric $\mathrm{C} / \mathrm{C}$ device (cell voltage 1.6 V). The activated carbon used for the symmetric device is the same as for the $\mathrm{C} / \mathrm{BSCF}$ device. $\mathrm{C} / \mathrm{C}, \mathrm{C} / \mathrm{BSCF}$ and $\mathrm{FeWO}_{4} / \mathrm{BSCF}$ cells have been fully charged to their respective maximum cell voltage, i.e. from 0 to $1.6 \mathrm{~V}, 1.6 \mathrm{~V}$ and $1.4 \mathrm{~V}$, 
respectively. The corresponding total charges stored $\mathrm{Q}_{\max }$ are 252, 67 and $44 \mathrm{mC}$, respectively. The self-discharge profile (plot $v s$ the time) measured after a 3 hours polarization at maximum cell voltage is shown in Fig. 6. Half of the cell voltage (i.e. when half of totals charges stored are released) was reached in 10 and 47 hours respectively for the $\mathrm{C} / \mathrm{BSCF}$ and $\mathrm{FeWO} / \mathrm{BSCF}$ devices. Self-discharge currents of $\mathrm{C} / \mathrm{BSCF}$ and $\mathrm{FeWO}_{4} / \mathrm{BSCF}$ are 9 and $4 \mu \mathrm{A} . \mathrm{F}^{-1}$, respectively (calculations to determine self-discharge current are described in SI). This is respectively 6 and 14 times lower than the self-discharge current of the $\mathrm{C} / \mathrm{C}$ device which is $57 \mu \mathrm{A} . \mathrm{F}^{-1}$ (with half of the cell voltage reached in only 4 hours). Despite a lower cycling ability, asymmetric $\mathrm{C} / \mathrm{BSCF}$ and $\mathrm{FeWO}_{4} / \mathrm{BSCF}$ devices demonstrate improved self-discharge characteristics compared to the symmetric $\mathrm{C} / \mathrm{C}$ device. A detailed analysis of the selfdischarge profiles is provided in SI (Fig. S10 and Tab. S6).

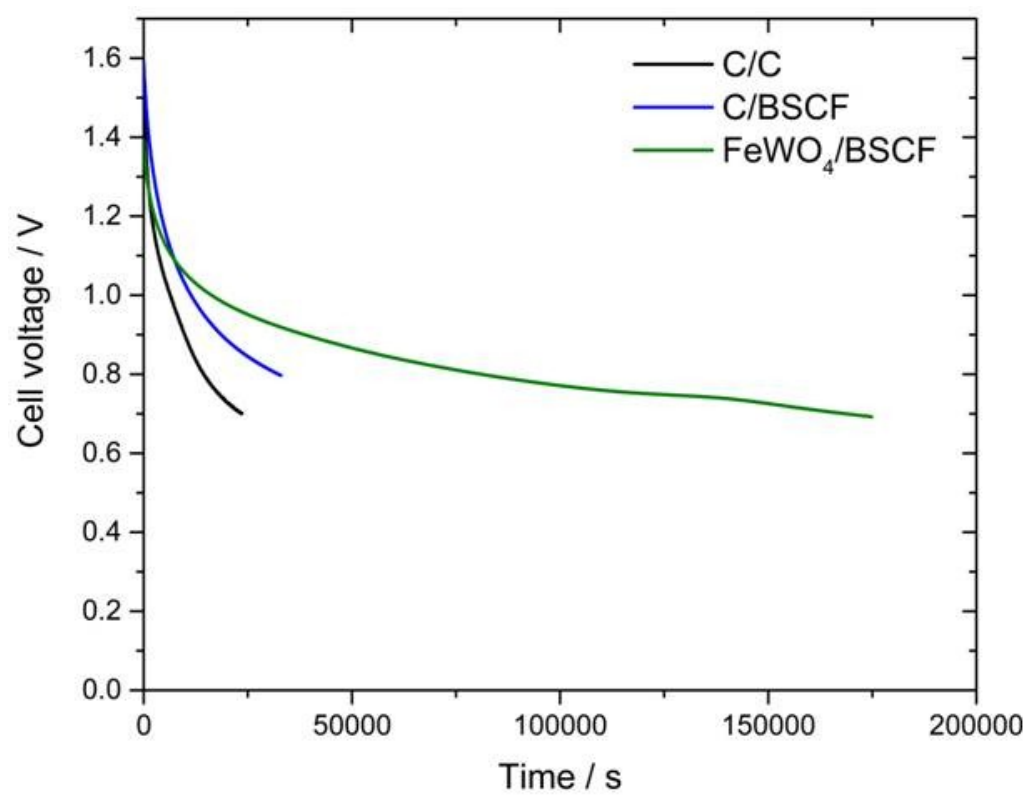

Fig. 6.Selfprofile of $\mathrm{C} / \mathrm{C}, \mathrm{C} / \mathrm{BSCF}$ and $\mathrm{FeWO}_{4} / \mathrm{BSCF}$ devices.

discharge

\section{Conclusion}

We report for the first time, two asymmetric electrochemical capacitors based on BSCF positive electrode material. The first one includes an activated carbon based negative 
electrode. The second, a $\mathrm{FeWO}_{4}$-based negative electrode, leading to a device with two high density multicationic oxides as electrode materials. The high densities of both oxides, together with the low capacitances of the electrodes led to lower specific performance than those of a symmetrical $\mathrm{C} / \mathrm{C}$ device. However, the high densities of $\mathrm{BSCF}$ and $\mathrm{FeWO}_{4}$ enable electrodes of smaller volume. On one hand, the small volume of electrodes was not sufficient to compensate the limited capacitance of the $\mathrm{FeWO}_{4} / \mathrm{BSCF}$ device. On the other hand, the high density of BSCF, associated to the high capacitance of activated carbon electrode led to similar volumetric energy density as for the $\mathrm{C} / \mathrm{C}$ devices, despite a limited capacitance. At low current density (0.2-0.4 A. $\left.\mathrm{g}^{-1}\right)$, the $\mathrm{C} / \mathrm{BSCF}$ device volumetric energy density was even greater than that of the $\mathrm{C} / \mathrm{C}$ device, at $2.3 \mathrm{Wh} . \mathrm{L}^{-1}$ (relative to the volume of electrodes and current collectors). Furthermore, both devices presented attractive cycling abilities upon cycling with a capacitance retention of $88 \%$ over 10,000 cycles for the $\mathrm{C} / \mathrm{BSCF}$ device and $83 \%$ over 45,000 cycles for the $\mathrm{FeWO}_{4} / \mathrm{BSCF}$ device. It is important to notice that such a long cycling test of an asymmetric device built on two pseudocapacitive oxides is scarce in the literature. Furthermore, asymmetric devices present better self-discharge characteristics than the $\mathrm{C} / \mathrm{C}$ device. Asymmetric devices built on two pseudocapacitive multicationic oxides could be an attractive strategy to improve the volumetric energy density of electrochemical capacitors. However, in aqueous based electrolytes, large specific capacitances are mandatory to compete with symmetric $\mathrm{C} / \mathrm{C}$ devices, at least $100 \mathrm{~F}^{-\mathrm{g}^{-1}}$.

\section{Acknowledgements}


This work was supported by the French National Agency through IVEDS project - Improving the Volumetric Energy Density of Supercapacitors - ref ANR-15-CE05-0011.

\section{Notes}

The authors declare no competing financial interest

\section{References}

1 Conway, B. E. Electrochemical Supercapacitors: Scientific Fundamentals and Technological Applications. Kluwer Academic/Plenum Publishers (1999).

2 Long, J. W. et al. Asymmetric electrochemical capacitors-Stretching the limits of aqueous electrolytes. MRS Bulletin 36, 513-522 (2011).

3 Brousse, T., Bélanger, D. \& Long, J. W. To Be or Not To Be Pseudocapacitive? Journal of The Electrochemical Society 162, A5185A5189 (2015).

4 Trasatti, S. \& Buzzanca, G. Ruthenium dioxide: A new interesting electrode material. Solid state structure and electrochemical behaviour. Journal of Electroanalytical Chemistry and Interfacial Electrochemistry 29, A1-A5 (1971).

5 Zheng, J. P., Cygan, P. J. \& Jow, T. R. Hydrous Ruthenium Oxide as an Electrode Material for Electrochemical Capacitors. Journal of The Electrochemical Society 142, 2699-2703 (1995).

$6 \mathrm{Hu}, \mathrm{C} .-\mathrm{C}$. , Chen, W.-C. \& Chang , K.-H. How to Achieve Maximum Utilization of Hydrous Ruthenium Oxide for Supercapacitors. Journal of The Electrochemical Society 151, A281-A290 (2004).

7 Lee, H. Y. \& Goodenough, J. B. Supercapacitor Behavior with $\mathrm{KCl}$ Electrolyte. Journal of Solid State Chemistry 144, 220-223 (1999).

8 Toupin, M., Brousse, T. \& Bélanger, D. Charge Storage Mechanism of $\mathrm{MnO}_{2}$ Electrode Used in Aqueous Electrochemical Capacitor. Chemistry of Materials 16, 3184-3190 (2004).

9 Ghodbane, O., Pascal, J.-L. \& Favier, F. Microstructural Effects on ChargeStorage Properties in $\mathrm{MnO}_{2}$-Based Electrochemical Supercapacitors. ACS Applied Materials \& Interfaces 1, 1130-1139 (2009).

10 Cottineau, T., Toupin, M., Delahaye, T., Brousse, T. \& Bélanger, D. Nanostructured transition metal oxides for aqueous hybrid electrochemical supercapacitors. Applied Physics A 82, 599-606 (2006).

11 Wu, N.-L., Wang, S.-Y., Han, C.-Y., Wu, D.-S. \& Shiue, L.-R. Electrochemical capacitor of magnetite in aqueous electrolytes. Journal of Power Sources 113, 173-178 (2003). 
12 Choi, D., Blomgren, G. E. \& Kumta, P. N. Fast and Reversible Surface Redox Reaction in Nanocrystalline Vanadium Nitride Supercapacitors. Advanced Materials 18, 1178-1182 (2006).

13 Lucio-Porto, R. et al. VN thin films as electrode materials for electrochemical capacitors. Electrochimica Acta 141, 203-211 (2014).

14 Liu, T. C., Pell, W. G., Conway, B. E. \& Roberson, S. L. Behavior of Molybdenum Nitrides as Materials for Electrochemical Capacitors: Comparison with Ruthenium Oxide. Journal of The Electrochemical Society 145, 1882-1888 (1998).

15 Shown, I., Ganguly, A., Chen, L.-C. \& Chen, K.-H. Conducting polymerbased flexible supercapacitor. Energy Science \& Engineering 3, 2-26 (2015).

16 Boota, M. et al. Pseudocapacitive Electrodes Produced by Oxidant-Free Polymerization of Pyrrole between the Layers of 2D Titanium Carbide (MXene). Advanced Materials 28, 1517-1522 (2016).

17 Goubard-Bretesché, N., Crosnier, O., Favier, F. \& Brousse, T. Improving the Volumetric Energy Density of Supercapacitors. Electrochimica Acta 206, 458-463 (2016).

18 Crosnier, O. et al. Polycationic oxides as potential electrode materials for aqueous-based electrochemical capacitors. Current Opinion in Electrochemistry 9, 87-94 (2018).

19 Mefford, J. T., Hardin, W. G., Dai, S., Johnston, K. P. \& Stevenson, K. J. Anion charge storage through oxygen intercalation in $\mathrm{LaMnO}_{3}$ perovskite pseudocapacitor electrodes. Nature Materials 13, 726 (2014).

20 Hwang, D. K., Kim, S., Lee, J.-H., Hwang, I.-S. \& Kim, I.-D. Phase evolution of perovskite $\mathrm{LaNiO}_{3}$ nanofibers for supercapacitor application and p-type gas sensing properties of $\mathrm{LaOCl}-\mathrm{NiO}$ composite nanofibers. Journal of Materials Chemistry 21, 1959-1965 (2011).

21 Cao, Y., Lin, B., Sun, Y., Yang, H. \& Zhang, X. Symmetric/Asymmetric Supercapacitor Based on the Perovskite-type Lanthanum Cobaltate Nanofibers with Sr-substitution. Electrochimica Acta 178, 398-406 (2015).

22 Lü, J. et al. A preliminary study of the pseudo-capacitance features of strontium doped lanthanum manganite. RSC Advances 5, 5858-5862 (2015).

23 Cao, Y., Lin, B., Sun, Y., Yang, H. \& Zhang, X. Sr-doped Lanthanum Nickelate Nanofibers for High Energy Density Supercapacitors. Electrochimica Acta 174, 41-50 (2015).

24 Abdollahifar, M. et al. High-performance carbon-coated $\mathrm{ZnMn}_{2} \mathrm{O}_{4}$ nanocrystallite supercapacitors with tailored microstructures enabled by a novel solution combustion method. Journal of Power Sources 378, 90-97 (2018).

25 Kuo, S.-L., Lee, J.-F. \& Wu, N.-L. Study on Pseudocapacitance Mechanism of Aqueous $\mathrm{MnFe}_{2} \mathrm{O}_{4}$ Supercapacitor. Journal of The Electrochemical Society 154, A34-A38 (2007).

26 Kuo, S.-L. \& Wu, N.-L. Electrochemical characterization on $\mathrm{MnFe}_{2} \mathrm{O}_{4} /$ carbon black composite aqueous supercapacitors. Journal of Power Sources 162, 1437-1443 (2006).

27 Chang, S.-K. et al. Structural and electrochemical properties of manganese substituted nickel cobaltite for supercapacitor application. Electrochimica Acta 67, 67-72 (2012).

28 Goubard-Bretesché, N., Crosnier, O., Payen, C., Favier, F. \& Brousse, T. Nanocrystalline $\mathrm{FeWO}_{4}$ as a pseudocapacitive electrode material for high volumetric energy density supercapacitors operated in an aqueous electrolyte. Electrochemistry Communications 57, 61-64 (2015). 
29 Shanmugavani, A., Murugeswari, R., Sanjeeviraja, C. \& Selvan, R. K. Nanocrystalline Pyrochlore $\mathrm{La}_{2} \mathrm{Sn}_{1.6} \mathrm{Zr}_{0.4} \mathrm{O}_{7}$ as a New Candidate for Supercapacitor Electrodes. Journal of Nanoscience and Nanotechnology 15, 2790-2797 (2015).

30 Lannelongue, $\mathrm{P}$. et al. Investigation of $\mathrm{Ba}_{0.5} \mathrm{Sr}_{0.5} \mathrm{Co}_{x} \mathrm{Fe}_{1-x} \mathrm{O}_{3-\delta}$ as a pseudocapacitive electrode material with high volumetric capacitance. Electrochimica Acta 271, 677-684 (2018).

31 Goubard-Bretesché, N., Crosnier, O., Buvat, G., Favier, F. \& Brousse, T. Electrochemical study of aqueous asymmetric $\mathrm{FeWO}_{4} / \mathrm{MnO}_{2}$ supercapacitor. Journal of Power Sources 326, 695-701 (2016).

32 Liu, P. et al. $\mathrm{Ba}_{0.5} \mathrm{Sr}_{0.5} \mathrm{Co}_{0.8} \mathrm{Fe}_{0.2} \mathrm{O}_{3-5}$-based dual-gradient cathodes for solid oxide fuel cells. Ceramics International 44, 4516-4519 (2018).

33 Cheng, X., Fabbri, E., Kim, B., Nachtegaal, M. \& Schmidt, T. J. Effect of ball milling on the electrocatalytic activity of $\mathrm{Ba}_{0.5} \mathrm{Sr}_{0.5} \mathrm{Co}_{0.8} \mathrm{Fe}_{0.2} \mathrm{O}_{3}$ towards the oxygen evolution reaction. Journal of Materials Chemistry A 5, 1313013137 (2017).

34 Habiballah, A. S., Jani, A. M. M., Mahmud, A. H., Osman, N. \& Radiman, S. Facile synthesis of $\mathrm{Ba}_{0.5} \mathrm{Sr}_{0.5} \mathrm{CO}_{0.8} \mathrm{Fe}_{0.2} \mathrm{O}_{3-\delta}$ (BSCF) perovskite nanowires by templating from nanoporous anodic aluminium oxide membranes. Materials Chemistry and Physics 177, 371-378 (2016).

35 Tan, L. A. et al. Influence of powder synthesis methods on microstructure and oxygen permeation performance of $\mathrm{Ba}_{0.5} \mathrm{Sr}_{0.5} \mathrm{Co}_{0.8} \mathrm{Fe}_{0.2} \mathrm{O}_{3-\delta}$ perovskitetype membranes. Journal of Membrane Science 212, 157-165 (2003).

36 Wang, H. H., Tablet, C., Feldhoff, A. \& Caro, H. Investigation of phase structure, sintering, and permeability of perovskite-type $\mathrm{Ba}_{0.5} \mathrm{Sr}_{0.5} \mathrm{Co}_{0.8} \mathrm{Fe}_{0.2} \mathrm{O}_{3-5}$ membranes. Journal of Membrane Science 262, 20-26 (2005).

37 Kovács, T. N. et al. Preparation of iron tungstate $\left(\mathrm{FeWO}_{4}\right)$ nanosheets by hydrothermal method. Materials Research Bulletin 95, 563-569 (2017).

38 Niu, L. et al. Simple Synthesis of Amorphous $\mathrm{NiWO}_{4}$ Nanostructure and Its Application as a Novel Cathode Material for Asymmetric Supercapacitors. ACS Applied Materials \& Interfaces 5, 8044-8052 (2013).

39 Balducci, A., Belanger, D., Brousse, T., Long, J. W. \& Sugimoto, W. Perspective-A Guideline for Reporting Performance Metrics with Electrochemical Capacitors: From Electrode Materials to Full Devices. Journal of The Electrochemical Society 164, A1487-A1488 (2017).

40 Soeda, K., Yamagata, M. \& Ishikawa, M. Outstanding features of alginatebased gel electrolyte with ionic liquid for electric double layer capacitors. Journal of Power Sources 280, 565-572 (2015).

41 Liu, Y. \& Zhitomirsky, I. Electrochemical supercapacitor based on multiferroic BiMn $\mathrm{O}_{5}$. Journal of Power Sources 284, 377-382 (2015).

42 Brousse, T. et al. Long-term cycling behavior of asymmetric activated carbon/ $\mathrm{MnO}_{2}$ aqueous electrochemical supercapacitor. Journal of Power Sources 173, 633-641 (2007).

43 Raut, S. S. et al. Zinc Ferrite Anchored Multiwalled Carbon Nanotubes for High-Performance Supercapacitor Applications. European Journal of Inorganic Chemistry 2018, 137-142 (2018).

$44 \mathrm{Su}, \mathrm{Y}$. \& Zhitomirsky, I. Hybrid $\mathrm{MnO}_{2}$ /carbon nanotube-VN/carbon nanotube supercapacitors. Journal of Power Sources 267, 235-242 (2014).

45 Brousse, T. \& Bélanger, D. A Hybrid $\mathrm{Fe}_{3} \mathrm{O}_{4} / \mathrm{MnO}_{2}$ Capacitor in Mild Aqueous Electrolyte. Electrochemical and Solid-State Letters 6, A244-A248 (2003). 